\title{
Purchasing Power Parity and Structural Instability in the US/UK Exchange Rate
}

\begin{abstract}
:
The aim of this study is to determine if nonlinearities have affected purchasing power parity (PPP) since 1885. Also using recent advances in the econometrics of structural change we segment the sample space according to the identified breaks and look at whether the PPP condition holds in each sub-sample and whether this involves linear or non-linear adjustment. Our results suggest that during some sub-periods, PPP holds, although whether it holds or not and whether the adjustment is linear or nonlinear, depends primarily on the type of exchange rate regime in operation at any point in time.
\end{abstract}




\section{Introduction}

The popular purchasing power parity (PPP) condition has been one of the most frequented areas of research over recent years and for a good reason; not only is it a key assumption especially in general equilibrium models of exchange rate determination, but also it entails substantial implications for international trade and capital movements. The evidence on PPP however has been surprisingly mixed. ${ }^{1}$ Interestingly, Taylor (2006) suggests that the evidence on whether this condition holds or not has systematically varied over the last thirty years. In the 1970s the evidence was largely positive. During the 1980s many studies failed to support the existence of PPP, but more recent studies have been more supportive, particularly over the long run. Therefore, it seems that the evidence depends not only on the econometric techniques that are used but also on the data spans that are examined. This study aims to identify the structural breaks in the data, then test for long-run PPP using cointegration which assumes adjustment is asymmetric, based on the Enders and Siklos (2001) approach. This contributes to the literature by using a new approach to identifying structural breaks, based on the variance as well as the mean and also using the non-linear cointegration approach to determine whether different types of exchange rate regime adjust in different ways.

The time-dependence of the evidence on PPP is not actually surprising. Specific to the UK/US exchange rate which is the focus of this paper, over the last hundred years there have been numerous changes to the exchange rate regime used by the UK and

\footnotetext{
${ }^{1}$ For a comprehensive review of the PPP literature see either Taylor and Taylor (2004) or Taylor (2006). In addition for a discussion of many of the problems and puzzles associated with PPP and the real exchange rate, see (Taylor and Taylor, 2004).
} 
USA, beginning with the Gold standard at the turn of the last century, then involving the Bretton-Woods fixed exchange rate regime, which collapsed in 1973. This required that the UK Sterling was pegged within narrow limits to the price of Gold and therefore other currencies including the US dollar. When this system failed, both the UK and USA moved to a managed floating regime. The UK also became a member of the European Exchange Rate Mechanism (ERM) in 1990, but subsequently was forced out in September 1992. It is only natural that such changes manifest themselves as structural changes (i.e. breaks) in the stochastic process of exchange rates. Failure to take them into account leads inevitably to biased results and consequently to inappropriate inferences.

A growing strand of the literature particularly over the last two decades has tried to address this issue and robustify its results by employing several approaches for the identification of such structural changes. Probably the most popular approach to determine the number and timing of breaks, primarily due to its simplicity, is to use exogenous information. Enders (1988) for example, one of the first who tried to address this issue, tests for differences between fixed and floating eras. He used the Bretton-Woods agreement to define the fixed era, the period lasting until April 1971 and as the floating era the period after January 1973. More recently, Zumaquero and Urrea (2002) go a step further to propose three main sources of breaks for European currencies namely the oil crisis, the beginning of the European Monetary System (EMS) in the late 1970s and the volatility in the EMS during the early 1990s. A number of studies have concentrated on determining the breaks endogenously, these include Hegwood and Papell (1998), who find evidence of "Quasi-PPP” and Papell and Prodan (2006) who use unit root tests which incorporate structural change whilst 
maintaining the long-run mean, again finding some evidence of trend-PPP. Other studies such as Prodan (2008) use the Bai test to determine multiple structural breaks in the mean. However, the well-known issue of breaks in the variance of such processes, which stems from the nature of exchange rate regimes, as fixed regimes are inherently characterised by a low variance of the exchange rate, is typically neglected.

Probably the most important contribution to this strand of the literature is the recognition that breaks present in the stochastic process of the exchange rates might also be linked to important, and often country-specific, economic events that are not, at least directly, relevant to the exchange rates regimes. For example, throughout the time period examined in this study there have been a number of events in the European Union, which will have impacted on the UK to a greater extent than the US. Such events to be considered, include the two World Wars, the failure of the Gold standard or the formation of the European single currency in 1999, where the UK had a policy of prepare for joining, but waiting for an opportune time to do so.

However, this contribution also constitutes the main methodological discrepancy of this approach; other completely irrelevant and most likely country specific events that are not taken into account might also induce breaks in the exchange rates. Furthermore, the timing of each break is unlikely to correspond directly to the timing of the event that induces this break - lead or lag effects are very typical in financial markets. It appears that data-driven methods are not only interesting but also paramount in ensuring that inference is not severely 'contaminated' by the presence of unidentified breaks. 
A second approach to identifying the breaks is to work with panel data (see for example Papell, 2002). In this way, there is enough information available to determine the timing of each break by data-driven methods and therefore evidence on whether PPP holds are more robust. However, this approach is based on the assumption that each break occurs at the same point in time across all countries in the panel. Naturally, this is a fairly strong assumption since it is quite unlikely that all panel members respond in exactly the same way and are affected only by the same common events.

The most robust method for testing the PPP condition is to first identify the number and timing of breaks in a time-series context. One such possibility is to endogenise breaks with some form of regime-switching. Engel and Kim (1999) use such an approach with models which include both the permanent and transitory component of the real exchange rate switching between three regimes of low, medium and high variance. Another possibility is to detect any existing breaks using non-parametric time-series methods and then superimpose these breaks onto the model that is used to test the PPP condition. In this case, the additional advantage is that there is substantially more flexibility in selecting the approach to test the PPP condition since the only prerequisite is that the data spans do not contain the identified breaks. As new approaches to testing for the PPP condition become available, such flexibility is a highly desirable characteristic of a methodological procedure and this is why this framework is adopted in this paper. 
In addition to identifying breaks we also use cointegration tests which allow for asymmetric adjustment, which can account for differing exchange rate regimes. Different exchange rate regimes will allow for differing levels of asymmetric adjustment possibly depending on the levels of intervention in the foreign exchange markets. This is particularly the case when a currency is under protracted pressure to stay within a particular range around a specific par value, so requiring more intervention when it is near the limits of its range, as in the Bretton-Woods system, than away from the edge of its band.

Enders and Dibooglu (2001) suggest asymmetric adjustment in prices as a further justification for using a non-linear approach to cointegration, as prices have a tendency to be sticky downwards. Enders and Dibooglu (2001) find strong evidence of non-linear adjustment and cointegration using a number of currencies with Germany and France as the base. Other studies that have incorporated various forms of non-linear adjustment into PPP tests include Panos et al. (1997), Taylor and Sarno (1998) and Bahmani-Oskooee et al. (2007).

Overall, the aim of this paper is to determine whether Purchasing Power Parity (PPP) is affected by the presence of structural breaks in the mean and/or variance, and the presence of asymmetries for the UK/US dollar since 1885, when the earliest data is available. In this way, we aspire to fill an important gap in the existing literature since research in this area is limited, which can be attributed primarily to the difficulties that exist in implementing robust econometric methods in identifying existing breaks 
in the mean and/or variance. ${ }^{2}$ Drawing upon recent advances in the econometrics of structural change, we use the 'Nominating-Awarding' procedure of Karoglou (2010) for the identification of breaks. Then, the existence of a long-run PPP relationship is tested for each sub-sample using cointegration analysis developed by Enders and Siklos (2001) the particular strength of which is that it weakens the ad-hoc assumption of having symmetric adjustment.

The remainder of the paper is structured as follows. Section 2 presents a brief description of the model and methodology while Section 4 discusses the results. A final section summarises and concludes with the policy implications.

\section{Model and Methodology}

In general, the approach we adopt here is to identify the number and timing of all breaks that exist in each series. Then, based on the sub-periods (segments) that these breaks define, to estimate for each segment the standard PPP model:

$$
\ln e_{t}=\alpha_{0}+\alpha_{1} \ln p_{t}+\alpha_{2} \ln p_{t}^{*}+u_{t}
$$

where $e_{t}$ is the bilateral exchange rate in terms of US dollars to UK pound Sterling, $p_{t}$ is the US price level and $p_{t}^{*}$ is the UK price level. Unlike the tests for stationarity of the real exchange rate, this approach does not assume strict proportionality of the

\footnotetext{
${ }^{2}$ Perron and Vogelsang, 1992 and Parkes and Savvides, 1999 could be viewed as studies in this area since while working with the real Sterling exchange rates they find that it is piecewise stationary, which provides support for long-run PPP. Also, Kapetanios, 2002 and Kapetanios et al. (2003) tests for the presence of a unit root against a specific number of structural breaks and shows that a nonlinear approach to the stationarity of the real exchange rate is more powerful than the standard linear ADF type tests.
} 
exchange rate and relative prices. According to Enders and Siklos (2001) non-linear adjustment can be incorporated into the tests for cointegration by allowing movements away from the long-run equilibrium to follow a threshold autoregressive (TAR) process.

$$
\Delta u_{t}=I_{t} \rho_{1} u_{t-1}+\left(1-I_{t}\right) \rho_{2} u_{t-1}+\varepsilon_{t}
$$

where $I_{t}$ is the Heaviside indicator such that:

$$
I_{t}=\left\{\begin{array}{l}
1 \text { if } u_{t-1} \geq 0 \\
0 \text { if } u_{t-1}<0
\end{array}\right.
$$

Enders and Siklos (2001) show that if the null hypothesis of $\rho_{1}=\rho_{2}=0$ is rejected i.e. if there is evidence of cointegration, then a further test of whether $\rho_{1}=\rho_{2}$ can be used to determine whether the adjustment to the long-run equilibrium is asymmetric. If the above null hypothesis is not rejected, i.e. if the adjustment is symmetric, then this is a special case of the Engle-Granger test for cointegration. Given that the test for non-linear cointegration follows a non-standard distribution, the critical values are available from Enders and Dibooglu (2001).

Enders and Siklos (2001) also suggest a further test based on the momentumthreshold autoregressive (MTAR) approach. In this case the approach is the same as the above except the following Heaviside indicator is used ${ }^{3}$ :

$$
I_{t}=\left\{\begin{array}{l}
1 \text { if } \Delta \mathrm{u}_{\mathrm{t}-1} \geq 0 \\
0 \text { if } \Delta u_{t-1}<0
\end{array}\right.
$$

\footnotetext{
${ }^{3}$ This study assumes the threshold value is 0 as we are interested if it is above or below its long-run PPP value, although Enders and Dibooglu (2001) also try other threshold values.
} 
This model suggests that a series has more momentum in one direction than the other. Finally we estimate the following non-linear error correction models, where there is evidence of cointegration:

$$
\Delta \ln e_{t}=\alpha_{0}+\tau_{1} I_{t} u_{t-1}+\tau_{2}\left(1-I_{t}\right) u_{t-1}+\alpha_{1} \Delta \ln e_{t-1}+\alpha_{2} \Delta \ln p_{t-1}+\alpha_{3} \Delta \ln p_{t-1}^{*}+v_{t}
$$

Where $\Delta \ln e_{t}$ and $\Delta \ln e_{t-1}$ are the differenced log of the exchange rate at time $t$ and $t-1 . \Delta \ln p_{t-1}$ and $\Delta p_{t-1}^{*}$ are the differenced log of the domestic and foreign price levels at time $t-1$ respectively. The remainder of this section describes the method for obtaining the cointegrating relations after taking into account the existence of breaks both in the mean and variance of each series. This procedure involves two stages; first, 'nominating' dates for breakdates and second 'awarding' the breakdate property to certain nominations as suggested in Karoglou (2010).

\subsection{The 'Nominating breakdates'stage}

The 'Nominating breakdates' stage is about the procedure which is used to identify some dates as possible ('nominated') breakdates. In recent years, a number of statistical tests have developed for that reason, several of which are employed for the purposes of this investigation. ${ }^{4}$ Specifically, we use the following tests:

(a) I\&T (Inclan and Tiao, 1994)

(b) $\mathrm{SAC}_{1}$ (The first test of Sansó, Aragó, and Carrion, 2004)

(c) $\mathrm{SAC}_{2}{ }^{\mathrm{BT}}, \mathrm{SAC}_{2}{ }^{\mathrm{VH}}$ (The second test of Sansó, Aragó, and Carrion, 2004, with the Bartlett kernel and the Newey-West automatic bandwidth selection procedure, and

\footnotetext{
${ }^{4}$ Note that although it is not done in this paper, it is relatively trivial to condition on observables - in the simplest case by nominating the 'official' or 'widely accepted' breakdates of each series.
} 
the Vector Autoregressive HAC or VARHAC kernel of den Haan and Levin, 1998 respectively)

(d) $K \& L_{B T}, K \& L_{Q S}, K \& L_{V H}$ (The refined by Andreou and Ghysels, 2002 version of the Kokoszka and Leipus, 1999 test with the Bartlett kernel, the Quadratic Spectral kernel, and the VARHAC kernel respectively).

There are a number of reasons why these tests have been selected to identify the structural changes in each of the series. First, although all of these tests are designed to detect a structural change in the volatility dynamics, Karoglou (2006) ${ }^{5}$ shows that many cumulative sum (CUSUM) type tests (including all the above) do not discriminate between shifts in the mean and shifts in the variance. For the purpose of this paper, this is a plausible feature since all types of breaks need to be considered. A second reason for selecting these CUSUM-type tests is that their properties for strongly dependent series have been extensively investigated (e.g. Andreou and Ghysels, 2002, Sansó, Aragó, and Carrion, 2004, Karoglou, 2006) and there is evidence that they perform satisfactorily under the most common ARCH-type processes. Thus, even when there is a break in a conditionally heteroskedastic process these tests can detect it, that is, the tests do not exhibit size distortions and they have considerable power even when the assumption of within-segment homoskedasticity is relaxed in order to include ARCH-type structures. In fact, (c) and (d) have some plausible properties even in the presence of IGARCH effects Nevertheless, Karoglou (2006) shows that the relative performance of each of the above tests depends on the underlying data generating process (DGP). ${ }^{6}$ Consequently, since the true DGP is not

\footnotetext{
${ }^{5}$ This work generalised the results of Bos and Hoontrakul (1998) who refer to the I\&T test.

${ }^{6}$ For example, the I\&T is found to be the most sensitive to the existence of volatility breaks for independent and identically distributed data, but suffers severe size distortions for strongly dependent
} 
known, it is preferable to use them all and select the breakdate according to an appropriate set of rules. ${ }^{7}$

The above tests can also be used to identify multiple breaks in a series. This is achieved by incorporating the break tests in an iterative scheme (algorithm) and applying them to sub-samples of the series. In this paper, the employed algorithm comprises of the following six steps:

1. Calculate the test statistic under consideration using the available data.

2. If the statistic is above the critical value split the particular sample into two parts at the corresponding point.

3. Repeat steps 1 and 2 for the first segment until no more (earlier) change-points are found.

4. Mark this point as an estimated change-point of the whole series.

5. Remove the observations that precede this point (i.e. those that constitute the first segment).

6. Consider the remaining observations as the new sample and repeat steps 1 to 5 until no more change-points are found.

data or for non-mesokurtic distributions. In contrast, the $\mathrm{K} \& \mathrm{~L}$ and the $\mathrm{SAC}_{2}$ variants do not exhibit size distortions in these cases but their power is smaller, while $\mathrm{SAC}_{1}$ does not exhibit size distortions for non-mesokurtic data and although it does for strongly dependent data, its power is higher than $\mathrm{K} \& \mathrm{~L}$ and $\mathrm{SAC}_{2}$. Sansó, Aragó, and Carrion, (2004) derive some theoretical results on the properties of $\mathrm{I} \& \mathrm{~T}, \mathrm{SAC}_{1}$, and $\mathrm{SAC}_{2}$ for data generating processes with different levels of kurtosis while Andreou and Ghyssels (2002) provide some simulation evidence for I\&T and K\&L.

${ }^{7}$ For example, a selection rule could suggest that a breakpoint can be considered only if two tests have identified it; or a breakpoint can be considered only if the resulting segments contain more than 10 observations. 
The above algorithm is implemented with each of the (single breakdate CUSUMtype) test statistics described above (i.e. I\&T, $\mathrm{SAC}_{1}, \mathrm{SAC}_{2}{ }^{\mathrm{BT}}, \mathrm{SAC}_{2}{ }^{\mathrm{QS}}, \mathrm{SAC}_{2}{ }^{\mathrm{VH}}$, $\left.\mathrm{K} \& \mathrm{~L}_{\mathrm{BT}}, \mathrm{K} \& \mathrm{~L}_{\mathrm{QS}}, \mathrm{K} \& \mathrm{~L}_{\mathrm{VH}}\right)$ and is applied to each series in ascending and descending time order so as to avoid potentially existing masking effects. The nominated breakdates for each series are simply all those which have been detected in both cases.

\subsection{The 'Awarding breakdates' stage}

The 'Awarding breakdates' stage is about the procedure which is used to choose which of the nominated breakdates are actual breakdates. In this paper, the procedure in essence is about uniting contiguous nominated segments (i.e. segments that are defined by the nominated breakdates) unless one of the following conditions is satisfied:

(i) the means of the contiguous segments are statistically different (as suggested by the t-test and the Satterthwaite-Welch t-test which is more robust when the contiguous segments do not have the same variance)

(ii) the variances of the contiguous segments are statistically different (as suggested by the battery of tests which is described below)

This testing procedure is repeated until no more segments can be united, that is, until no condition of the above is satisfied for any pair of contiguous segments.

With regards to the battery of tests mentioned in (ii), it involves several statistical tests designed to test for the homogeneity of variances of different samples - in this case these samples are two contiguous segments. These tests constitute a different approach to the CUSUM-type tests described previously in that they test for the homogeneity of variances of distinct samples, that is, without encompassing the time- 
series dimension of the data. ${ }^{8}$ They include the standard F-test, the Siegel-Tukey test with continuity correction (Siegel and Tukey, 1960, and Sheskin, 1997), the adjusted Bartlett test (see Sokal and Rohlf, 1995, and Judge, et al., 1985), the Levene test (1960) and the Brown-Forsythe (1974) test.

Overall, the F-test requires equal sample sizes and is sensitive to departures from normality. On the other hand, the Siegel-Tukey test is based on the assumption that the samples are independent and have the same median. The Bartlett test is also robust when the sample sizes are not equal despite it still being sensitive to departures from normality. Its adjusted version makes use of a correction factor for the critical values and the arcsine-square root transformation of the data to conform to the normality assumption. The Levene test is an alternative to the Bartlett test albeit less sensitive to departures from normality. Finally, the Brown-Forsythe test is a modified Levene test (substituting the group mean by the group median) and appears to be superior in terms of robustness (when scores are highly skewed or samples are relatively small) and power.

\section{Data and Results}

We use monthly data that runs from January 1885 to June of $2009^{9}$. It consists of the bilateral US\$/UK£ exchange rates and the respective producer price indexes (PPI)

\footnotetext{
${ }^{8}$ Therefore, they provide the same value even if the observations of each segment are randomly ordered. In contrast, statistics that are based on sequential methods (such as the CUSUM tests) are influenced by the order of the observations.

${ }^{9}$ The data is an updated version of that used by Kim and Engel (1999), whom we would like to thank for access to this dataset, which is also available on their website. This was an updated version used by Grilli and Kaminsky 1991.
} 
which reflects international prices more accurately than other measures such as the consumer price index.

Table 1 and Table 2 report the results of the 'Nominating-Awarding' procedure which suggest that there are 9 structural changes present in all series, namely in $1914 \mathrm{~m} 8$, $1921 \mathrm{~m} 7,1940 \mathrm{~m} 12$ and 1951m03, 1976m03, $1980 \mathrm{~m} 05,1993 \mathrm{~m} 05$ and 2000m06 and $2008 \mathrm{~m} 01$. All of these breaks can be associated, with the usual leads and lags effects, with distinctive changes to the UK and US economies. The first break in $1914 \mathrm{~m} 8$ is associated with the beginning of World War 1 and the abandoning of the Gold standard. The break in $1921 \mathrm{~m} 7$ is associated with the ending of World War 1 in 1918 and the subsequent realignment of the currency as the pound was allowed to depreciate against the dollar from $\$ 4.76$ to $\$ 3.40$ during 1920 . The next break is in $1940 \mathrm{~m} 12$, which is again associated with the outbreak of war as well as the pegging of the pound to the US dollar. All of these first three breaks were also identified by Engel and Kim (1999) using a regime switching approach. However the 1951 break identified here and some of the following breaks were not identified in the previous studies, this break is associated with the changes to the international monetary system following the creation of the Bretton-Woods system in 1947, followed by the devaluation of Sterling in 1949 by some $30.5 \%$ and then subsequent devaluations by other countries.

During the early 1950s the international monetary system enjoyed an era of relative stability, so in effect 1951 could be seen as the move from relatively volatile exchange rates to a short period of relatively stable exchange rates during the early part of the Bretton Woods era. This relative stability continued into the early 1960s, 
but which ended in the late 1960s and early 1970s when the Bretton-Woods system became increasingly untenable, before finally collapsing in 1973. Following this capital controls were removed in 1975 by the US, which produces the next break in 1976 m03. The break in 1980 m05 follows the UK joining the European Monetary System (EMS) in 1979 and the removal of the UK's main capital controls.

Then in 1992 the UK was forced to leave the European Exchange Rate Mechanism (ERM) after it had come under increasing pressure throughout 1991. One reason for the pressure on Sterling was the unification of Germany in 1990 and the subsequent increase in German interest rates to curtail its inflation. This put pressure on all the ERM members, but especially the UK as it had arguably entered at an over-valued exchange rate. So the next break in $1993 \mathrm{~m} 05$ follows the UK leaving the ERM and subsequent volatility in both Sterling and the currencies of other ERM members ${ }^{10}$, coinciding with a general break identified in Zumaquero and Urrea (2002) and also Engel and Kim (1999). In the middle of 1993 following months of speculative attacks on the currencies of France and other ERM members, the system in effect collapsed, in so far as the bands were extended to plus or minus $15 \%$, adding to volatility in international foreign exchange markets. Following its exit in 1992, the UK currency joined that of the US as a managed float, which began an era of relative stability

\footnotetext{
${ }^{10}$ The small deviations of the timing of the identified breaks from the official dates of the specific events can easily be attributed to the well known lead-lag effects that exist in financial markets. For example, lead effects arise quite often when much of the change is priced into the currencies before the actual change occurs; similarly, lag effects can arise in some cases either when the markets are uncertain about the true picture that will arise from a policy change and therefore they act only after the event takes place or when the effect of a policy change takes time to propagate to the real economy.
} 
between the dollar and Sterling, as it remained at about 1.6 dollars to one pound Sterling.

The final break appears in $2000 \mathrm{~m} 5$, which coincides with the currency volatility across the world, which was occasioned by the formation of the European single currency (Euro) in 1999. The dollar appreciated gradually in the years leading up to its formation and the subsequent months until in 2005, the value of the dollar peaked, thereafter depreciating against most currencies including the pound. So in many respects although no big economic event occurred in 2000, it was a year in which the sharp appreciation of the dollar against the UK pound ended and a new era of depreciation began, which subsequently lasted until 2008 .

Tables 1-4, as mentioned present some properties of the segmented data and where the breaks are located ${ }^{11}$, while Tables 5 and 6 present the results from applying the Enders and Siklos non-linear cointegration technique. ${ }^{12}$ Where there was evidence of autocorrelation, lagged dependent variables were added until it was removed, in no cases did this require more than a single lag. The results from the tests using all the data provide evidence of cointegration, but no evidence of non-linearity as the different samples with differing levels of non-linear adjustment in effect cancel each

\footnotetext{
11 The model estimates are based on the jointly segmented series, i.e based on the breaks of all the series while the break tests are on the individually (based on their own breaks only) segmented series, so there are more breaks in the series, when PPP is estimated than the individual variables.

${ }^{12}$ Linear cointegration was also tried using the Johansen test and this also suggested evidence of cointegration during some sectors but not all. For a discussion of the use of the Johansen approach to cointegration with PPP, see Sederis (2006).
} 
other out. However in the subsamples, the results are much different, with no evidence of cointegration, except for 1885 to 1914 and 1951 to 1976 using the TAR model. Only between 1951 and 1976 is there evidence of non-linearity though.

Table 6 contains the MTAR cointegration results and again there is evidence of cointregration over the entire data set but no evidence of non-linearity. With this approach there is evidence of non-linear cointegration for 1885 to 1914 and 1921 to 1940, although only the latter suggests any non-linearity. The evidence of cointegration tends to occur more in sub-samples where the exchange rate is either fixed as in the Gold Standard or pegged as in the Bretton-Woods agreement, this is similar to the results in Enders (1988) although as with these results the evidence in that study was not conclusive. However during the first sample in which the gold standard operated from 1885 to 1914 , the UK and USA were not under pressure to revalue and the system was reasonably stable. For the TAR model, the 1951 to 1976 sample covers the Bretton-Woods system of fixed exchange rates, during which the UK currency was under intense pressure, leading to a revaluation in 1967. For this reason only when the exchange rate was away from equilibrium and near its lower bound, would the UK and US authorities intervene to prevent it moving outside of its bounds. Similarly with the 1921 to 1940 sub-sample, which roughly covers the post 1st World War gold standard and where again there were pressures as the US currency strengthened at the expense of the UK, which may be why the MTAR model works better than the TAR model for this era, as there was momentum in one direction for these currencies throughout most of this era. This pressure led to a break-down of the exchange rate system in 1933, when the UK left. 
Table 7 contains the results for the non-linear error correction models ${ }^{13}$, which are produced where there has been evidence of cointegration, for both the TAR and MTAR versions of the models. This allows us to compare the speeds of adjustment back to equilibrium across the different sub-samples. For both TAR and MTAR models the error correction terms are highly significant for the 1914 to 1921 time span, with roughly equal rates of adjustment back to equilibrium of $30 \%$, which is very quick and reflects the stability of this initial era of the Gold Standard. However with the TAR model and the 1951 to 1976 sub-sample, the speeds of adjustment are very different with no adjustment when positive and $6.6 \%$ adjustment back to equilibrium when negative. This reflects the way in which the pound was under pressure during much of this time period, with the authorities ignoring it when it was above equilibrium, but having to intervene when below due to the weakness of the UK currency. With the MTAR model the opposite is the case, with adjustment only for positive values. Overall the application of the techniques used in this study have ensured the models are fitted well. With exchange rates it is important to test for breaks in both the variance as well as mean when identifying structural breaks. In addition non-linear cointegration and error correction models produce a better fit when the exchange rates are fixed due to the significance of the non-linear terms. This ensures the results in the paper will be more reliable.

\section{Conclusion}

This study tests for PPP whilst accounting for any significant structural breaks in the conditional mean and/or variance of the series. Using the US/UK dollar exchange rate

\footnotetext{
${ }^{13}$ Only the exchange rate error correction models are included here, the price models are available on request.
} 
since 1885 , we identify non-parametrically a number of structural breaks, especially during the occasions during which the UK and USA moved between fixed and floating exchange rates. We find that these policy decisions lead to substantial moves in the exchange rate which have driven this currency away from its PPP value.

In general, our findings suggest that there are periods during which the PPP condition does not hold. When this is examined in conjunction with the timing of the identified breaks, our results indicate that the presence or otherwise of PPP and non-linear adjustment is dependent on a number of factors, such as whether exchange rates are fixed and the degree of intervention in foreign exchange markets as well as the extent to which countries co-ordinate their macroeconomic policies. There is evidence of both a TAR and MTAR based asymmetric adjustment during the fixed exchange rate eras, this can be explained by the authorities only intervening in the foreign exchange markets when the weaker currency is below its par value and close to its lower band, suggesting the currency is weaker than predicted by PPP. Future research could concentrate on including some of the information in the structural breaks into the currency’s risk premium. 


\section{References}

Andreou, E. and Ghysels, E., 2002. Multiple breaks in financial market volatility dynamics. Journal of Applied Econometrics 70, 9 - 38.

Bahmani-Oskooee, M., Kutan, A. and Zhou, S., 2007. Testing PPP in the non-linear STAR framework. Economics Letters 94, 104-110.

Bos, T. and Hoontrakul, P., 1998. Estimation of mean and variance episodes in the price return of the stock exchange of Thailand, SASIN of Chulalongkorn University. Brown, M. and Forsythe, A., 1974. Robust tests for equality of variances. Journal of the American Statistical Association 69, 364-67.

Den Haan, W.J. and Levin, W., 1998. Vector autoregressive covariance matrix estimation', manuscript, University of California, San Diego.

Enders, W., 1988. ARIMA and cointegration tests of PPP under fixed and flexible exchange rate regimes. Review of Economics and Statistics 70, 504-508.

Enders, W. and Dibooglu, S., 2001. Long-run Purchasing Power Parity with asymmetric adjustment. Southern Economic Journal 68, 433-445.

Enders, W. and Siklos, P., 2001. Cointegration and threshold adjustment. Journal of Business and Economic Statistics 19, 166-77.

Engel, C. and Kim, C-J.. 1999. The long-run U.S./U.K. real exchange rate. Journal of Money, Credit and Banking 31, 335-356.

Grilli, V. and Kaminsky, G., 1991. Nominal exchange rate regimes and the real exchange rate: Evidence from the United States and Great Britain, 1885 - 1986. Journal of Monetary Economics 27, 191-212.

Hegwood, N. D. and Papell, P.H., 1998. Quasi Purchasing Power Parity. International Journal of Finance and Economics 3, 279-289. 
Inclan, C. and Tiao, G.C., 1994. Use of cumulative sums of squares for retrospective detection of changes of variance. Journal of the American Statistical Association 89, $913-923$.

Kapetanios, G., 2002. Unit root testing against the alternative hypothesis of up to $m$ structural breaks. University of London Queen Mary Discussion paper No. 469.

Kapetanios, G., Y. Shin and Snell, A., 2003. Testing for a unit root in the non-linear STAR framework. Journal of Econometrics 112, 359-379.

Karoglou, M., 2006. On the detection of structural changes in volatility dynamics with applications. PhD Thesis, University of Leicester, Leicester.

Karoglou, M., 2010. Breaking down the non-normality of daily stock returns. European Journal of Finance 16. 79-95.

Kokoska, P. and Leipus, R., 1999. Testing for parameter changes in ARCH models. Lithuanian Mathematical Journal 39, 231 - 247.

Lamoureux, C. and Lastrapes, W., 1990. Persistence in variance, structural change and the GARCH model. Journal of Business Economics and Statistics 8, 225-234

Levene, H., 1960. In contributions to probability and statistics: Essays in honour of Harold Hotelling. I. Olkin et al. eds, Stanford University Press.

Panos, M., Nobay, A. and Peel, D., 1997. Transaction costs and non-linear adjustments in real exchange rates: An empirical investigation. Journal of Political Economy 105, 862-79.

Perron, P. and Vogelsang, T., 1992. Nonstationarity and level shifts with an application to Purchasing Power Parity. Journal of Business and Economic Studies $10,301-320$. 
Papell, D., 2002. The great appreciation, the great depreciation, and the Purchasing Power Parity hypothesis. Journal of International Economics 57, 51-82.

Papell, D. H. and Prodan, R., 2006. Additional evidence of long-run Purchasing Power Parity with restricted structural change. Journal of Money, Credit and Banking $38,1329-1349$.

Parkes, A. and Savvides, A., 1999. Purchasing Power Parity in the long-run and structural breaks: Evidence from real Sterling exchange rates. Applied Financial Economics 9, 117-127.

Prodan, (2008) "Potential Pitfalls in Determining Multiple Structural Changes with an Application to Purchasing Power Parity", Journal of Business Economics and Statistics 26, 50-65.

Sansó, A., Aragó, V. and Carrion, J., 2004. Testing for changes in the unconditional variance of financial time series. Revista de Economia Financiera4, 32-53.

Sheskin, D.J., 1997. Handbook of parametric and nonparametric statistical procedures. Boca Raton, FL: CRC press.

Siegel, S., and Tukey, J., 1960. A nonparametric sum of ranks procedures for relative spread in unpaired samples. Journal of the American Statistical Association 55, 42944.

Sokal, R.R. and Rohlf, F., 1995. Biometry: the principles and practise of statistics in biological research. New York, W.H. Freemand and Co.

Sideris, D., 2006. Testing for long-run PPP in a system context: Evidence for the US, Germany and Japan. Journal of International Financial Markets, Institutions and Money 16, 143-154.

Taylor, M.P., 2006. Real exchange rates and Purchasing Power Parity: Meanreversion in economic thought. Applied Economics 16, 1-17. 
Taylor, M.P. and Sarno, L., 1998. The behaviour of real exchange rates during the post-Bretton Woods period. Journal of International Economics 46, 281-312.

Taylor, A.M. and Taylor, M.P., 2004. The Purchasing Power Parity debate. Journal of Economic Perspectives 18, 135-158.

Zumaquero, A. and Urrea, R.P., 2002. Purchasing Power Parity: Error correction models and structural breaks. Open Economies Review 13, 5-26. 
Table 1. The results from the 'Nominating breakdates' stage

\begin{tabular}{|c|c|c|c|c|c|c|c|c|c|}
\hline & $I T$ & $\overline{A S C_{1}}$ & $A S C_{2}^{B T}$ & $A S C_{2} Q S$ & $\mathrm{ASC}_{2}{ }^{V H}$ & $K L_{B T}$ & $K L_{Q S}$ & $K L_{V H}$ & $L M T$ \\
\hline \multirow{4}{*}{$\begin{array}{l}\widetilde{\vdots} \\
\tilde{\Xi} \\
\tilde{s}\end{array}$} & 1921M07 & 1946M11 & 1946M11 & 1946M11 & 1946M11 & 1946M11 & 1946M11 & 1946M11 & 1946M11 \\
\hline & $1951 \mathrm{M} 03$ & 2001M01 & - & 2001M01 & - & - & 2001M01 & - & 2001M01 \\
\hline & 2000M06 & 2008M03 & - & 2008M03 & - & - & 2008M03 & - & 2008M03 \\
\hline & 2008M03 & - & - & - & - & - & - & - & - \\
\hline \multirow{4}{*}{ 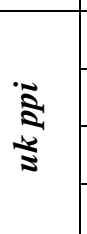 } & 1914M08 & 1914M08 & 1914M08 & 1914M08 & 1914M08 & 1914M08 & 1914M08 & 1940M11 & 1914M08 \\
\hline & 1940M12 & 1940M12 & 1940M12 & 1940M12 & 1940M12 & 1940M12 & 1940M12 & - & 1940M12 \\
\hline & 1980M05 & 1980M05 & - & 1980M05 & - & - & 1980M05 & - & 1980M05 \\
\hline & 2008M01 & $2008 \mathrm{M} 01$ & - & 2008M01 & - & - & $2008 \mathrm{M} 01$ & - & 2008M01 \\
\hline \multirow{3}{*}{ 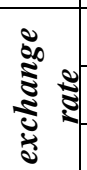 } & 1976M03 & - & - & - & - & - & - & - & - \\
\hline & 1993M05 & - & - & - & - & - & - & - & - \\
\hline & 2008M08 & - & - & - & - & - & - & - & - \\
\hline
\end{tabular}

Notes: The above refer to dates with year followed by month. See text for a description of the above tests. 'BT' refers to the use of the Bartlett kernel with the Newey-West automatic bandwidth selection procedure and 'VH' to the use of the VARHAC kernel.

Table 2. The results from the 'Awarding breakdates' stage.

\begin{tabular}{|c|c|c|c|c|c|c|c|}
\hline Segments (obs in 1st, 2nd) & t-test & S-Wt-test* & F-test & $\begin{array}{l}\text { Siegel- } \\
\text { Tukey }\end{array}$ & Bartlett & Levene & $\begin{array}{l}\text { Brown- } \\
\text { Forsythe }\end{array}$ \\
\hline ER1 \& $2(1094,206)$ & 0.18 & 0.13 & $3.1 * * *$ & $17.51 * * *$ & $139.62 * * *$ & $200.07 * * *$ & $203.42 * * *$ \\
\hline ER $2 \& 3(206,183)$ & -0.88 & -0.9 & $2.71 * * *$ & $5.43 * * *$ & $44.95 * * *$ & $33.44 * * *$ & $34.05 * * *$ \\
\hline ER3 \& $4(183,10)$ & $2.29 * *$ & 0.96 & $7.97 * * *$ & $3.69 * * *$ & $34.28 * * *$ & $44.2 * * *$ & $42 * * *$ \\
\hline UK ppi $1 \& 2(355,316)$ & -0.74 & -0.71 & $3.61 * * *$ & $6.37 * * *$ & $131.6^{* * * *}$ & $57.14 * * *$ & $57.04 * * *$ \\
\hline UK ppi $2 \& 3(316,473)$ & $-3.8 * * *$ & $-3.25 * * *$ & $7.77 * * *$ & $13.46^{* * *}$ & $385.37 * * *$ & $168.04 * * *$ & $169.88 * * *$ \\
\hline UK ppi $3 \& 4(473,332)$ & $6.04 * * *$ & $6.8 * * *$ & $5.17 * * *$ & $4.72 * * *$ & $218.84 * * *$ & $88.5 * * *$ & $58.22 * * *$ \\
\hline UK ppi 4 \& $5(332,17)$ & 0.15 & 0.07 & $5.92 * * *$ & $4.09 * * *$ & $41.58 * * *$ & $43.36 * * *$ & $37.13 * * *$ \\
\hline US ppi $1 \& 2(438,304)$ & -0.24 & -0.25 & $1.79 * * *$ & $2.28 * *$ & $28.83 * * *$ & $13.52 * * *$ & $11.94 * * *$ \\
\hline US ppi $2 \& 3(304,52)$ & -1.64 & $-1.98 *$ & $1.71 * * *$ & 0.16 & $5.49 * *$ & 0.25 & 0.2 \\
\hline US ppi $3 \& 4(52,591)$ & $2.4 * *$ & 1.5 & $3.2 * * *$ & $5.8 * * *$ & $43.9 * * *$ & $49.2 * * *$ & $48.73 * * *$ \\
\hline US ppi 4 \& $5(591,7)$ & $-1.69 *$ & -0.93 & 3.4 & $2.6 * * *$ & $6.54 * *$ & $5.74 * *$ & $5.62 * *$ \\
\hline US ppi $5 \& 6(7,86)$ & 0.69 & 0.68 & 1.01 & 0.55 & $<0.01$ & $<0.01$ & $<0.01$ \\
\hline US ppi $6 \& 7(86,15)$ & $2.06^{* *}$ & 1.18 & $5.91 * * *$ & $3.24 * * *$ & $26.7 * * *$ & $30.43 * * *$ & $25.2 * * *$ \\
\hline
\end{tabular}

Notes: See Table 1. S-W is Satherwaite-Welch t-test. ******* indicate significance at the 10,5 and $1 \%$ levels of significance. 
Table 3. Unit root tests for the series and the segments (in levels)

\begin{tabular}{|c|c|c|c|c|c|c|c|c|c|}
\hline levels & ADF & DFGLS & $\mathbf{P P}$ & KPSS & ERS & $\mathbf{N P}(1)$ & $\mathrm{NP}(2)$ & NP(3) & NP(4) \\
\hline$U K p p i$ & 3.6 & $25 * * *$ & $1.2 * * *$ & $5.9 * * *$ & -1.5 & 0.02 & $3.03 *$ & $0.43 * * *$ & -0.3 \\
\hline UK ppi 1 & $5.2 * * *$ & 2.3 & $130.2 * * *$ & $3.4 * * *$ & -1.7 & 1.4 & -1.1 & $16.53 * * *$ & $0.5 * * *$ \\
\hline UK ppi 2 & $1.4 * * *$ & 1.01 & 3.1 & $205.4 * * *$ & $1 * * *$ & $-3.3 * *$ & -0.1 & -1.91 & $16.8 * * *$ \\
\hline UK ppi 3 & $214 * * *$ & $0.4 * * *$ & $3.2 * * *$ & 3.5 & $4.9 * * *$ & $2.1 * * *$ & -1.01 & $-1.77 *$ & -1.4 \\
\hline UK ppi 4 & -1.7 & $22.6 * * *$ & $1 * * *$ & $4.6^{* * * *}$ & -5.6 & $203.1 * * *$ & $4.5 * * *$ & -1.65 & $-2.1 * *$ \\
\hline UK ppi 5 & -1.6 & 1.3 & $105.7 * * *$ & $1.3 * * *$ & -1.6 & 0.6 & $24.6 * * *$ & $0.43 *$ & -2.3 \\
\hline US ppi & -1.4 & $3.5 * * *$ & -2.6 & $174.9 * * *$ & $0.3 * * *$ & 0.5 & -0.1 & $3.93 * *$ & 0.3 \\
\hline US ppi 1 & $1.5^{* * *}$ & 1.1 & $-2.7 * *$ & -0.2 & $4.5 * * *$ & $0.8^{* * * *}$ & -0.03 & $-6.79 *$ & $5 * * *$ \\
\hline US ppi 2 & $4.8^{* * *}$ & $3.1 * * *$ & -0.9 & -0.4 & $4.2 * * *$ & $47.6 * * *$ & $0.6 * * *$ & $-1.79 *$ & -5.3 \\
\hline US ppi 3 & -5.5 & $414.9 * * *$ & $0.5^{* *}$ & -0.3 & $4.3 * * *$ & $-5.2 * * *$ & $24 * * *$ & $0.26 * *$ & -1.6 \\
\hline US ppi 4 & -1.6 & 1.7 & $2.9 *$ & $1.2 * * *$ & $11.3 * * *$ & $-3 * * *$ & -0.7 & $3.81 * *$ & $0.3 * * *$ \\
\hline US ppi 5 & $0.3 * * *$ & $3.6 * * *$ & $-27.9 * * *$ & $9.6 * * *$ & $1.9 * * *$ & -2.6 & 0.1 & -0.99 & $4.7 * * *$ \\
\hline$E R$ & $3.1 * *$ & $4.7 * * *$ & $2.1 * * *$ & $-3.7 * * *$ & -1.9 & $479.1 * * *$ & 0.1 & -0.73 & -0.3 \\
\hline ER 1 & $4.1 * * *$ & 1.1 & $334.2 * * *$ & 0.1 & -0.6 & $6.3 *$ & $4.6 * * *$ & $3.53 * * *$ & -1 \\
\hline$E R 2$ & $3.2 * *$ & 1.1 & 1.9 & 0.9 & $0.3 * * *$ & $11.3 * * *$ & $-8.4 * *$ & $16.86^{* * * *}$ & $1 * * *$ \\
\hline ER 3 & $3.7 * * *$ & 1.4 & $3 * * *$ & 2.3 & $9.5 * * *$ & $1.8 * * *$ & $-2 * *$ & 0.11 & $18.9 * * *$ \\
\hline ER 4 & $220.9 * * *$ & $1 * * *$ & 1.9 & $2.9 * * *$ & -2.1 & $450.5 * * *$ & $0.2 * *$ & 0.05 & -0.6 \\
\hline
\end{tabular}


Table 4. Unit root tests for the series and the segments (in differences)

\begin{tabular}{|c|c|c|c|c|c|c|c|c|c|}
\hline log-diff & ADF & DFGLS & PP & KPSS & ERS & $\mathbf{N P}(1)$ & $\mathbf{N P}(2)$ & $\mathbf{N P}(3)$ & NP(4) \\
\hline$U K p p i$ & $-12.7 * * *$ & $-12.6 * * *$ & $-23.1 * * *$ & $0.4^{*}$ & 0.1 & $-278.1 * * *$ & $11.8 * * *$ & 0.04 & 0.1 \\
\hline UK ppi 1 & $-13.6^{* * *}$ & $-12.3 * * *$ & $-13.6 * * *$ & 0.3 & 0.8 & $-153.4 * * *$ & $-8.4 * * *$ & 0.05 & 0.7 \\
\hline UK ppi 2 & $-7.5 * * *$ & $-5.2 * * *$ & $-7.4 * * *$ & 0.2 & 0.4 & $-48.7 * * *$ & $-4.9 * * *$ & 0.1 & 0.5 \\
\hline UK ppi 3 & $-3.5 * * *$ & $-3.5 * * *$ & $-14.4 * * *$ & $0.7 * *$ & 1.3 & $-20.1 * * *$ & $-3.2 * * *$ & 0.16 & 1.3 \\
\hline UK ppi 4 & -2.4 & -0.3 & $-9.9 * * *$ & $1.8 * * *$ & $55 * * *$ & -0.4 & -0.4 & $1.12 * * *$ & $62.2 * * *$ \\
\hline UK ppi 5 & -1.5 & -1.6 & -1.7 & 0.2 & $5.6 * * *$ & -4 & -1.4 & $0.35^{* * *}$ & $6.2 * * *$ \\
\hline US ppi & $-14.7 * * *$ & $-9.1 * * *$ & $-28.8 * * *$ & 0.2 & 0.1 & $-134.5^{* * * *}$ & $-8.2 * * *$ & 0.06 & 0.2 \\
\hline US ppi 1 & $-9.3 * * *$ & $-7.9 * * *$ & $-15.2 * * *$ & 0.1 & 0.3 & $-95.1 * * *$ & $-6.9 * * *$ & 0.07 & 0.3 \\
\hline US ppi 2 & $-6.7 * * *$ & $-6.1 * * *$ & $-13.3 * * *$ & $0.5^{* *}$ & 0.4 & $-55.9 * * *$ & $-5.3 * * *$ & 0.09 & 0.4 \\
\hline US ppi 3 & $-5.2 * * *$ & -1.5 & $-21.3 * * *$ & $0.4^{*}$ & $2.1 *$ & -1.2 & -0.4 & $0.34 * * *$ & $10.7 * * *$ \\
\hline US ppi 4 & $-8.4 * * *$ & $-8.3 * * *$ & $-8.4 * * *$ & $0.4^{*}$ & 1 & $-45.4 * * *$ & $-4.6 * * *$ & 0.1 & 0.9 \\
\hline US ppi 5 & -1.7 & $-1.7 *$ & -1.7 & 0.2 & $5.6 * * *$ & -4.1 & -1.4 & $0.33 * * *$ & $6 * * *$ \\
\hline Exchange rates & $-26.2 * * *$ & $-24.6 * * *$ & $-25.7 * * *$ & 0.1 & 0.1 & $-613.7 * * *$ & $17.5 * * *$ & 0.03 & 0.1 \\
\hline Exchange rates 1 & $-22.4 * * *$ & $-20.8 * * *$ & $-22.1 * * *$ & 0.2 & 0.1 & $-446.1 * * *$ & $14.9 * * *$ & 0.03 & 0.1 \\
\hline Exchange rates 2 & $-9.6 * * *$ & $-2.8 * * *$ & $-9.7 * * *$ & 0.1 & 1 & $-15.1 * * *$ & $-2.7 * * *$ & $0.18 *$ & 1.8 \\
\hline Exchange rates 3 & $-11 * * *$ & $-1.7 *$ & $-12 * * *$ & 0.1 & 0.6 & -3.7 & -1.3 & $0.34 * * *$ & $6.7 * * *$ \\
\hline Exchange rates 4 & -0.3 & -0.5 & -0.3 & $0.4^{*}$ & $15.6^{* * *}$ & -0.7 & -0.3 & $0.47 * * *$ & $15.1 * * *$ \\
\hline
\end{tabular}

Note that only the KPSS has as null hypothesis that the series is stationary 
Table 5. Tests for Non-linear Cointegration using the TAR model

\begin{tabular}{|c|c|c|c|c|}
\hline Sample & $\rho_{1}$ & $\rho_{2}$ & Coint & $\rho_{1}=\rho_{2}$ \\
\hline $1885-1914 \mathrm{~m} 07$ & $\begin{array}{c}-0.316^{* * * *} \\
(5.863)\end{array}$ & $\begin{array}{c}-0.361 * * * \\
(6.100)\end{array}$ & $35.784^{*}$ & 0.326 \\
\hline $1914 \mathrm{~m} 081921 \mathrm{~m} 07$ & $\begin{array}{l}-0.069 \\
(0.992)\end{array}$ & $\begin{array}{c}-0.126 * * \\
(2.260)\end{array}$ & 3.046 & 0.643 \\
\hline $1921 \mathrm{~m} 08-1940 \mathrm{~m} 12$ & $\begin{array}{c}-0.063^{*} \\
(1.823)\end{array}$ & $\begin{array}{c}-0.089 * * * \\
(2.809)\end{array}$ & 5.497 & 0.301 \\
\hline $1941 \mathrm{~m} 01-1951 \mathrm{~m} 03$ & $\begin{array}{l}-0.016 \\
(0.806)\end{array}$ & $\begin{array}{c}-0.004 \\
(0.236)\end{array}$ & 0.357 & 0.234 \\
\hline $1951 \mathrm{~m} 04-1976 \mathrm{~m} 03$ & $\begin{array}{l}-0.012 \\
(0.707)\end{array}$ & $\begin{array}{c}-0.076 * * * \\
(3.781)\end{array}$ & $7.382 * *$ & $\begin{array}{c}5.684 * \\
*\end{array}$ \\
\hline $1976 \mathrm{~m} 04-1980 \mathrm{~m} 05$ & $\begin{array}{c}-0.038 \\
(0.672)\end{array}$ & $\begin{array}{c}-0.053 \\
(0.962)\end{array}$ & 0.679 & 0.033 \\
\hline 1980m06 - 1993 m05 & $\begin{array}{c}-0.057 * * \\
(2.569)\end{array}$ & $\begin{array}{c}-0.022 \\
(1.099)\end{array}$ & 3.904 & 1.384 \\
\hline $1993 \mathrm{~m} 06-2000 \mathrm{~m} 06$ & $\begin{array}{c}-0.245^{* *} \\
(2.454)\end{array}$ & $\begin{array}{c}-0.238 * * \\
(2.502)\end{array}$ & 5.882 & 0.003 \\
\hline $2000 \mathrm{~m} 07-2008 \mathrm{~m} 01$ & $\begin{array}{l}-0.087 \\
(1.512)\end{array}$ & $\begin{array}{c}-0.081 \\
(1.480)\end{array}$ & 2.200 & 0.005 \\
\hline 1885 m06 - 2009 m06 & $\begin{array}{c}-0.019 * * * \\
(3.013)\end{array}$ & $\begin{array}{c}-0.019 * * * \\
(3.484)\end{array}$ & $10.571 * * *$ & 0.000 \\
\hline
\end{tabular}

Notes: The fourth and fifth columns are F-statistics, ***,*** indicates significance at the $10 \%, 5 \%, 1 \%$ level, critical values taken from Enders and Dibooglu (2001)

Table 6. Tests for Non-linear cointegration using the MTAR model

\begin{tabular}{|c|c|c|c|c|}
\hline Sample & $\rho_{1}$ & $\rho_{2}$ & Coint & $\rho_{1}=\rho_{2}$ \\
\hline $1885 \mathrm{~m} 06-1914 \mathrm{~m} 07$ & $-0.352^{* * *}$ & $-0.327 * * *$ & $35.776^{* * *}$ & 0.100 \\
& $(5.822)$ & $(6.137)$ & & \\
$1914 \mathrm{~m} 08$ 1921m07 & $-0.151^{* * *}$ & -0.024 & 3.918 & 2.042 \\
& $(2.775)$ & $(0.349)$ & & \\
$1921 \mathrm{~m} 08-1940 \mathrm{~m} 12$ & $-0.115^{* * *}$ & -0.031 & $7.094 *$ & $3.350^{*}$ \\
& $(3.678)$ & $(0.890)$ & & \\
$1941 \mathrm{~m} 01-1951 \mathrm{~m} 03$ & $-0.038^{*}$ & 0.004 & 1.549 & 2.614 \\
& $(1.731)$ & $(0.299)$ & & \\
$1951 \mathrm{~m} 04-1976 \mathrm{~m} 03$ & $-0.060^{* * *}$ & -0.007 & 6.385 & $3.748^{*}$ \\
& $(3.559)$ & $(0.343)$ & & \\
$1976 \mathrm{~m} 04-1980 \mathrm{~m} 05$ & 0.002 & $-0.100^{*}$ & 1.558 & 1.740 \\
& $(0.037)$ & $(1.764)$ & & \\
$1980 \mathrm{~m} 06-1993 \mathrm{~m} 05$ & $-0.043 *$ & $-0.033 *$ & 3.242 & 0.113 \\
& $(1.936)$ & $(1.653)$ & & \\
$1993 \mathrm{~m} 06-2000 \mathrm{~m} 06$ & -0.094 & $-0.285 * * *$ & 5.249 & 2.006 \\
& $(0.956)$ & $(3.096)$ & & \\
$2000 \mathrm{~m} 07-2008 \mathrm{~m} 01$ & -0.040 & $-0.105^{*}$ & 1.938 & 0.678 \\
& $(0.755)$ & $(1.818)$ & & \\
$1885 \mathrm{~m} 06-2009 \mathrm{~m} 06$ & -0.019 & $-0.019 * * *$ & 5.419 & $7.267 *$ \\
& $(0.367)$ & $(3.269)$ & & \\
\hline
\end{tabular}

Notes: (T) and (M) refer to TAR and MTAR models respectively. 
Table 7. Non-linear Error Correction Models

\begin{tabular}{|c|c|c|c|c|c|c|}
\hline Sub-samples & $\mathrm{c}$ & residplus & $\begin{array}{c}\text { residmin } \\
\mathrm{us}\end{array}$ & $\Delta \mathrm{e}(-1)$ & $\begin{array}{c}\Delta \mathrm{ukp} \\
(-1)\end{array}$ & $\begin{array}{c}\Delta \mathrm{usp} \\
(-1)\end{array}$ \\
\hline (T)1885m06 - & 0.000 & $-0.297^{* *}$ & $-0.375^{* *}$ & -0.011 & -0.013 & 0.001 \\
$1914 \mathrm{~m} 07$ & $(0.397)$ & $(4.710)$ & $(5.409)$ & $(0.207)$ & $(0.948)$ & $(0.056)$ \\
$(\mathrm{T}) 1951 \mathrm{~m} 04-$ & -0.001 & 0.008 & $-0.067 * *$ & $0.476^{* *}$ & -0.145 & -0.009 \\
$1976 \mathrm{~m} 03$ & $(1.825)$ & $(0.485)$ & $(2.808)$ & $(8.789)$ & $(1.469)$ & $(0.104)$ \\
$(\mathrm{T}) 1885 \mathrm{~m} 03-$ & -0.000 & -0.013 & $-0.019^{*}$ & $0.378^{* *}$ & 0.005 & -0.024 \\
$2009 \mathrm{~m} 06$ & $(0.237)$ & $(1.942)$ & $(2.266)$ & $(15.346)$ & $(0.110)$ & $(0.597)$ \\
& & & & & & \\
$(\mathrm{M}) 1885 \mathrm{~m} 06$ & 0.00 & $-0.348^{* *}$ & $-0.321^{* *}$ & -0.010 & -0.013 & -0.000 \\
$-1914 \mathrm{~m} 07$ & $(0.013)$ & $(5.396)$ & $(5.649)$ & $(0.194)$ & $(0.917)$ & $(0.041)$ \\
$(\mathrm{M}) 1921 \mathrm{~m} 08-$ & 0.000 & $-0.096^{* *}$ & -0.023 & $0.366^{* *}$ & -0.001 & 0.142 \\
$1940 \mathrm{~m} 12$ & $(0.003)$ & $(3.034)$ & $(0.655)$ & $(5.435)$ & $(0.008)$ & $(1.006)$ \\
\hline
\end{tabular}

Notes: (T) is TAR model and (M) is from the MTAR model, the residminus and residplus are the error correction terms for negative and positive residuals respectively. 